\title{
Penetrating spine injury bisecting thoracic spinal canal with no significant neurological deficits-The midline cord syndrome
}

\author{
Bhaskar Sarkar $^{1} \cdot$ Kaustubh Ahuja $^{1} \cdot$ Arghya Kundu Choudhury $^{1} \cdot$ Rohit Jain $^{1}$
}

Received: 14 September 2018 / Revised: 28 October 2018 / Accepted: 31 October 2018

(c) International Spinal Cord Society 2018

\begin{abstract}
Introduction In India, the incidence of penetrating spine injury (PSI) is increasing because of the increased use of advanced ballistics (missile PSI) among military personnel and sophisticated tools and construction instruments like nail-guns or drills (non-missile PSI) among civilians. These injuries are associated with a risk of neurological damage, central nervous system infections, vascular injury, dural tear followed by CSF leakage, and spinal instability.

Case presentation A 35-year-old male presented with a non-missile PSI with retained iron nail bisecting his dorsal spinal cord, without any motor deficits. Patient presented with only left lower limb proprioceptive loss and L1-L3 paresthesia. Nail removal was done on emergent basis without any further neurological damage.

Discussion To the best of our knowledge, this presentation of a non-missile PSI and has not been previously reported. The specific clinical presentation of this distinct type of injury to the midline structures of the spinal cord is hence named "midline cord syndrome".
\end{abstract}

\section{Introduction}

The incidence of penetrating spine injury (PSI) is increasing in India due to the increased use of advanced ballistics (missile PSI) among military personnel and sophisticated tools and construction instruments like nail-guns and drills (non-missile PSI) among civilians. In contrast non-missile PSI from knife, shrapnel, gardening tools etc. appears to be decreasing due to easy availability of guns. Individuals with PSI frequently present with fixed neurological deficits and vascular injuries and may develop central nervous system infections, cerebrospinal fluid (CSF) leak following dural tear, lead toxicity or spinal instability [1-3]. Thorough preoperative planning is essential to prevent complications. This report describes a 35-year-old male with penetrating spine injury to his thoracic spine by a metallic foreign body

These authors contributed equally: Bhaskar Sarkar and Kaustubh Ahuja

Kaustubh Ahuja

kaustubh1@live.in

1 Department of Orthopaedic Surgery, All India Institute of Medical Sciences, Rishikesh 249203 Uttarakhand, India (iron nail) shot with a nail gun. It was retained in the T8-T9 intervertebral disc space, without any major neurological deficit.

\section{Case presentation}

A 35-year-old male presented to the Emergency Department of AIIMS Rishikesh, with a $7 \mathrm{~h}$ history of accidental PSI caused by a metallic foreign body (iron nail) from a nail gun. He received treatment in the form of tetanus toxoid injection and analgesics elsewhere. On presentation, the patient had excruciating back pain with a Visual Analog Scale (VAS) score as high as 9/10. On inspection after log rolling, the metallic foreign body (FB) - iron nail head was visible outside the skin at the mid-back region without any bleeding. Neurologically, the patient had no motor loss, although he had bilateral sensory loss to pin prick from L1 to L3 and proprioception loss in left lower limb. Neurological examination was done as per international standards for neurological classification of spinal cord injury with diagnosis of T12 AIS E spinal cord injury(SCI) (Fig. 1) [4]. Plain radiographs revealed the presence of intact FB in the T8-T9 intervertebral space encroaching into the disc space. Pre-operative CT scan imaging of the spine revealed a metallic FB, entering along the right margin of $\mathrm{T} 9$ spinous 
Fig. 1 Neurological examination of the patient at presentation as per International Standards of Neurological Classification for Spinal Cord Injury

Fig. 2 Pre-operative CT scan imaging (axial and sagittal sections) showing of metallic FB (iron nail) bisecting the T8-T9 spinal canal
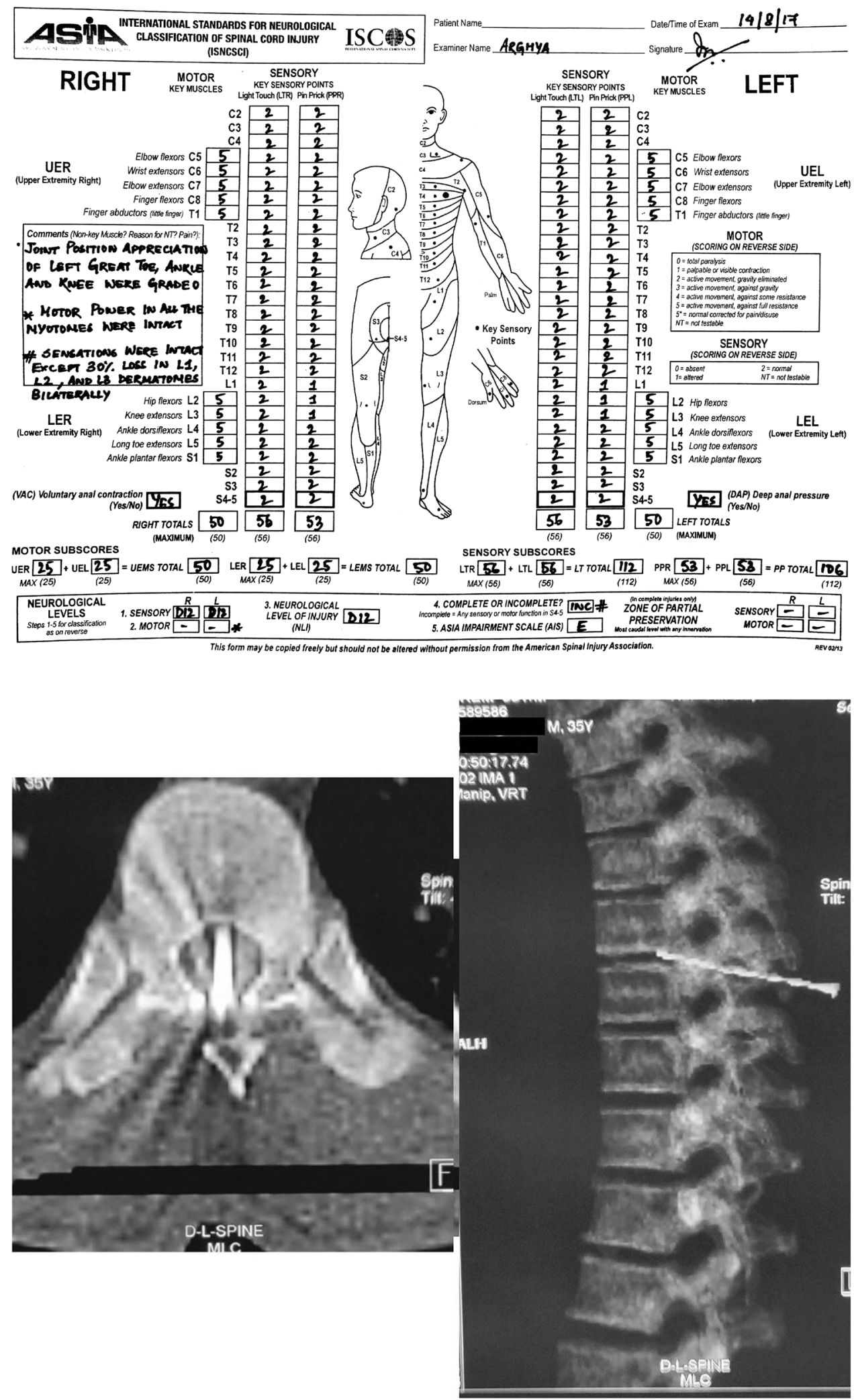

The patient was positioned prone (Fig. 3) and the T8-T9 spinous process was exposed using a dorsal midline approach. The nail was found passing through the interlaminar space along the right margin of the D9 spinous 


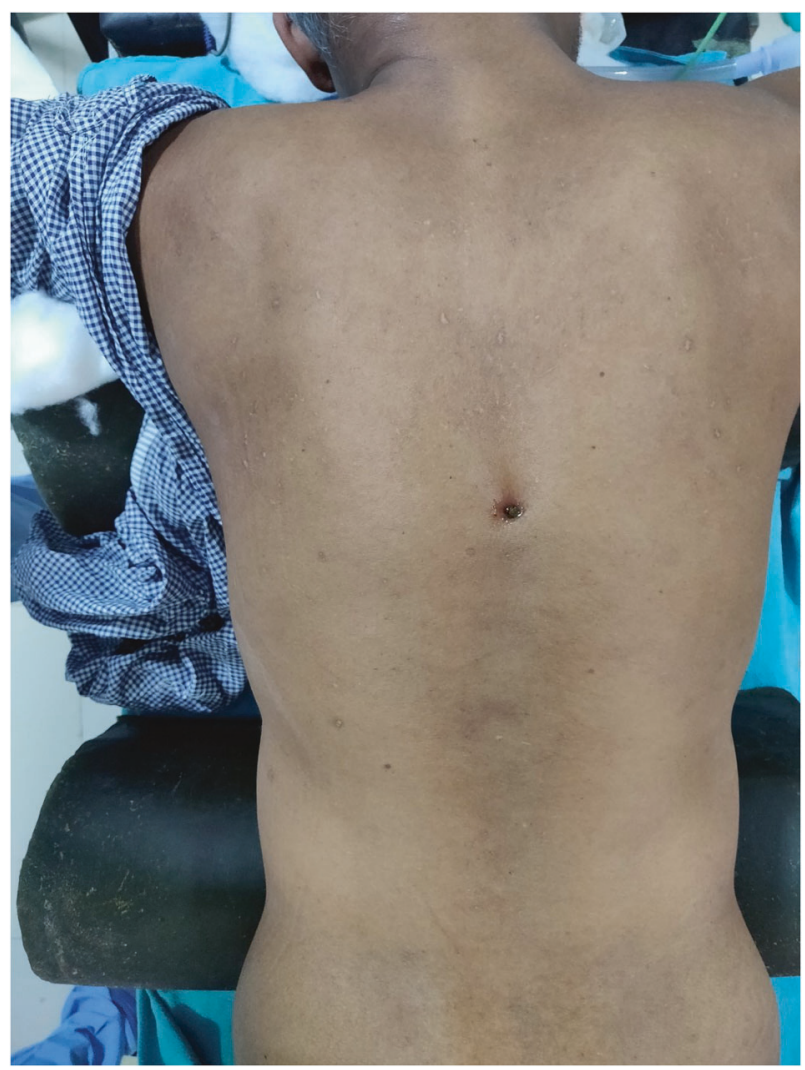

Fig. 3 Patient positioned prone on the OR table with iron nail head visible outside the skin in the mid-back region

process. A lower T8 and upper T9 partial laminectomy was done preserving the facet joints. The nail was found penetrating through the dura (Fig. 4a). The nail (FB) of size $5.7 \mathrm{~cm}$ in length and $0.5 \mathrm{~cm}$ in diameter (Fig. 4b) was carefully removed and the dural rent was repaired first with 6-0 prolene and then sealed off using TISSEEL (Baxter, USA). The seal was augmented using autologous fascial graft and no CSF leak was confirmed using an intraoperative Valsalva maneuver under anesthesia. The facet joints were not disturbed and therefore, any further consideration for posterior stabilization was aborted.

Post-operatively the patient was started on acetazolamide $(25 \mathrm{mg}$ ) four times daily. He was allowed mobilization in bed; Foley catheter was maintained and stool softeners were prescribed. Broad spectrum antibiotics were continued for $72 \mathrm{~h}$ post-operatively. Post-operative neurological examination was unchanged and plain radiographs showed complete removal of the foreign body. MRI showed complete bisection of the cord into equal halves with slight edema around the midline structures. (Fig. 5). His postoperative stay in the hospital was uneventful and the patient was discharged on day 12. A repeat neurological examination was conducted every 6 to 8 weeks and complete sensory recovery was seen at around 12 months follow up.
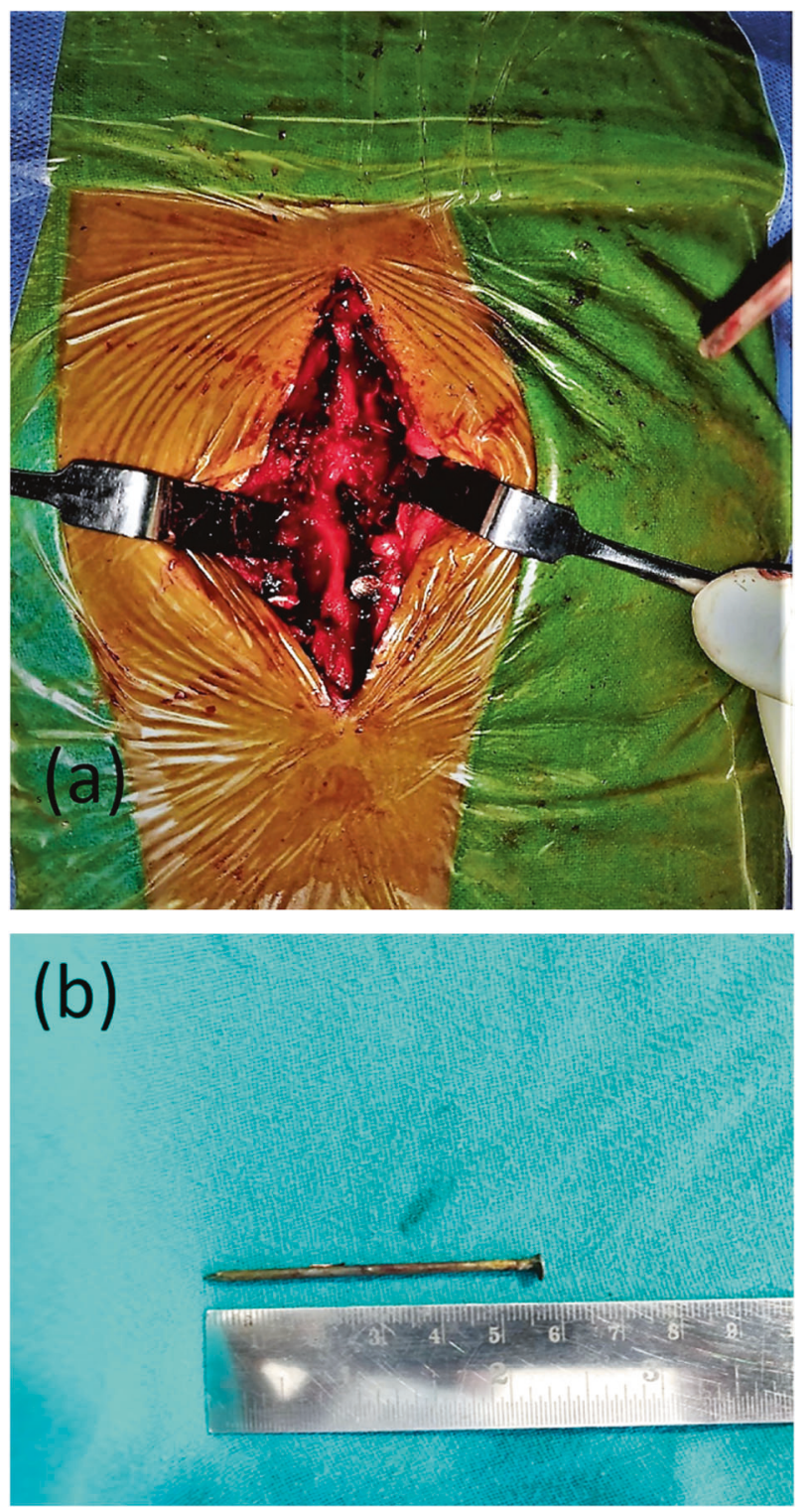

Fig. 4 a Facet preserving D8 and D9 partial laminectomy done and dura exposed showing iron nail piercing through the dura and the rent caused by the same. b Intact iron nail following its removal

\section{Discussion}

Accidental non-missile PSI with a retained foreign object is rare and presentation without any significant neurological deficits is extremely uncommon. Lipschitz and Block et al. reported 130 cases with retained foreign bodies in only $2.3 \%$. In their series $30 \%$ of the persons had complete while $70 \%$ had incomplete SCI [5]. Peacock et al. reported 450 cases with $70-80 \%$ of persons with incomplete SCIs primarily Brown-Sequard syndrome and 66\% with good recovery [6]. In an Indian series of 11 non-missile PSI injuries, Thakur et al. reported four cases with retained foreign bodies and eight cases with a fixed neurological 


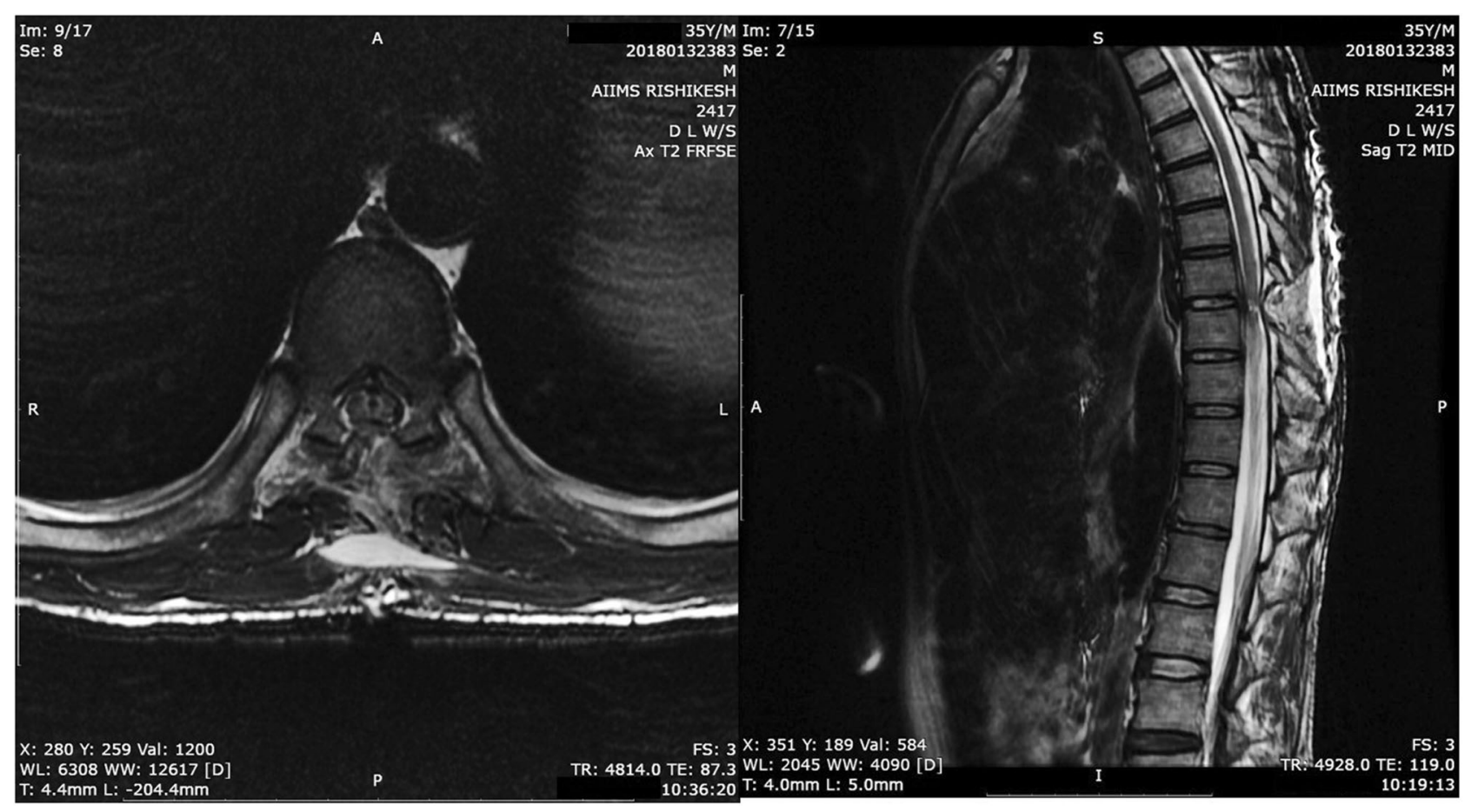

Fig. 5 Post-operative T2-weighted axial and sagittal MRI films with bisection of spinal cord along the path of removed iron nail with edema in midline cord structures

deficit [7]. Brown-Sequard syndrome is the most common neurological presentation seen in almost two-third cases with penetrating SCIs $[6,8,9]$.

Our patient had a retained $5.7 \mathrm{~cm}$ iron nail bisecting the spinal canal at T8-T9 with no significant neurological damage. This case was different from those previously described in that it was accidental rather than an assault. This most likely explains the retained foreign body in the spinal canal unlike stab injuries where the weapon is generally retracted back by the assaulter. Intact neurology gives us an opportunity to understand the neurological presentation of patients with injury to midline structures of spinal cord. Two aspects that play an important role in deciding the neurological presentation are (1) the kinetic energy (K. E) of the foreign body and (2) the structures damaged in its trajectory and around it. Singh et al. in their article have given an elaborate description of the K.E imparted by a nail gun to an iron nail and its comparison to a missile K.E. PSI caused by a nail gun behave as low velocity projectiles with a K.E of $1.64 \mathrm{ft}-\mathrm{lbs}$, much less than an average missile K.E of around $1480 \mathrm{ft}-\mathrm{lbs}$ [10]. Low K.E. is responsible for lesser cord damage due to lesser temporary cavitary damage and thus lesser neurological deficit as compared to missile penetrating injuries [11].

In this case, the nail bisected the spinal canal at the level of T8-T9 almost exactly into two halves. According to the cross-sectional anatomy of cord, the midline structures at possible risk are (1) dorsal column (fasciculus gracilis), (2) anterior and posterior gray commissures, (3) anterior white commissure, and (4) anterior spinal artery. Injury to the anterior white commissures containing the decussating fibers of lateral spinothalamic tracts of L1-L3 region correlates with partial sensory loss in L1-L3 dermatome bilaterally as experienced by the patient. Injury to left fasciculus gracilis is consistent with proprioceptive loss experienced by the patient in left lower limb. Decussating anterior corticospinal and spinocerebellar tracts have no clinically appreciable neurological deficits. This distinct neurological presentation is specific to injury to the midline structures of the spinal cord and hence the term "midline cord syndrome".

Regarding prevention of complications, broad spectrum antibiotics were continued for up to $72 \mathrm{~h}$ post-operatively, until the surgical wound status was checked [12]. We did not use methylprednisolone as it is shown to have adverse effects in patients with penetrating injury to the spinal cord [13]. One of the concern in thoracolumbar SCI is the presence of the artery of Adamkiewicz, occurring in $73 \%$ between D8 and D10 [14]. It serves as an important branch of the anterior spinal artery supplying the lower third of the spinal cord [15]. AB Rogers et al. have reported injury to artery of Adamkiewicz due to isolated stab wound at the thoracolumbar region [16]. With the pattern of neurological loss and radiological confirmation of the trajectory of the iron nail, injury to the artery of Adamkiewicz was 
considered less likely, hence we did not obtain a preoperative angiogram.

Pre-operative plain radiographs were mandatory to determine the exact location the iron nail, and the CT scan imaging complements it. However pre-operative MRI scans are not recommended if ferromagnetic properties of FB are unknown [17, 18]. Surgical exploration for the retained FB is recommended to prevent long-term complications like myelopathy [1], intramedullary abscess [2], progressive neurological deficits [18], and pseudomeningocele [8] formation.

Our patient was carefully monitored for any neurological deterioration post-operatively due to any compressive hematoma or any central nervous system infections, but he had no complications during his post-operative stay. He recovered completely which is consistent with the literature where neurological deficits due to the penetrating injuries to the spinal cord have recovered in $66 \%$ of the cases after surgical removal [18].

Penetrating spine injuries are grave injuries usually associated with substantial neurological deficits. This was a rare clinical presentation and mode of injury where the iron nail was bisecting the spinal cord, thereby injuring the midline structures of the cord and presenting with specific neural deficits including loss of proprioception and paresthesia in upper lumbar dermatomal distribution. To the best of our knowledge, this particular presentation has not been described previously.

\section{Compliance with ethical standards}

Conflict of interest The authors declare that they have no conflict of interest.

\section{References}

1. Jones FD, Woosley RE. Delayed myelopathy secondary to retained intraspinal metallic fragment. Case report. J Neurosurg. 1981;55:979-82.
2. Wright RL. Intramedullary spinal cord abscess. J Neurosurg. 1965;23:208-10.

3. Velmahos GC, Degiannis E, Hart K, Souter I, Saadia R. Changing profiles in spinal cord injuries and risk factors influencing recovery after penetrating injuries. J Trauma. 1995;38:334-7.

4. Kirshblum SC, Burns SP, Biering-Sorensen F, Donovan W, Graves DE, Jha A, et al. International standards for neurological classification of spinal cord injury (Revised 2011). J Spinal Cord Med. 2011;34:535-46.

5. Lipschitz R, Block J. Stab wounds of the spinal cord. Lancet Lond Engl. 1962;28:169-72.

6. Peacock WJ, Shrosbree RD, Key AG. A review of 450 stabwounds of the spinal cord. South Afr Med J Suid-Afr Tydskr Vir Geneeskd. 1977;51:961-4.

7. Thakur RC, Khosla VK, Kak VK. Non-missile penetrating injuries of the spine. Acta Neurochir (Wien). 1991;113:144-8.

8. de Villiers JC, Grant AR. Stab wounds at the craniocervical junction. Neurosurgery. 1985;17:930-6.

9. Heary RF, Vaccaro AR, Mesa JJ, Balderston RA. Thoracolumbar infections in penetrating injuries to the spine. Orthop Clin North Am. 1996;27:69-81.

10. Singh DK, Gupta A, Mittal R, Saggar V. Penetrating injury to cervical spine from a nail gun. Indian Neurotrauma. 2009;6:147-9.

11. Holt GR, Kostohryz G. Wound ballistics of gunshot injuries to the head and neck. Arch Otolaryngol Chic Ill 1960. 1983;109:313-8.

12. Nasser R, Nakhla J, Sharif S, Kinon M, Yassari R. Penetrating thoracic spinal cord injury with ice pick extending into the aorta. A technical note and review of the literature. Surg Neurol Int. 2016;7(Suppl 28):S763-6.

13. Prendergast MR, Saxe JM, Ledgerwood AM, Lucas CE, Lucas WF. Massive steroids do not reduce the zone of injury after penetrating spinal cord injury. J Trauma. 1994;37:576-9. discussion579-580.

14. Alleyne CH, Cawley CM, Shengelaia GG, Barrow DL. Microsurgical anatomy of the artery of Adamkiewicz and its segmental artery. J Neurosurg. 1998;89:791-5.

15. Takase K, Sawamura Y, Igarashi K, Chiba Y, Haga K, Saito H, et al. Demonstration of the artery of Adamkiewicz at multidetector row helical CT. Radiology. 2002;223:39-45.

16. Rogers FB, Osler TM, Shackford SR, Wald SL. Isolated stab wound to the artery of Adamkiewicz: case report and review of the literature. J Trauma. 1997;43:549-51.

17. Doğan S, Kocaeli H, Taşkapilioğlu MO, Bekar A. Stab injury of the thoracic spinal cord: case report. Turk Neurosurg. 2008;18:298-301.

18. Kulkarni AV, Bhandari M, Stiver S, Reddy K. Delayed presentation of spinal stab wound: case report and review of the literature. J Emerg Med. 2000;18:209-13. 